\title{
FABRICAÇÃO DE UMA EVAPORADORA DE METAIS COMO FORMA DE AGREGAR VALOR AOS SERVIÇOS DO MICROEMPREENDEDOR INDIVIDUAL ${ }^{1}$
}

\author{
MANUFACTURING OF A THERMAL EVAPORATOR AS A WAY OF \\ ADDING VALUE TO THE INDIVIDUAL MICROENTREPRENEUR \\ WORK
}

Recebido: 07/05/2018 - Aprovado: 29/6/2018 Publicado: 30/7/2018 Processo de Avaliação: Double Blind Review

\section{Diego Escudeiro ${ }^{2}$}

Graduado em Tecnologia em Manutenção Industrial

FATEC-Osasco

dyeggo_escudeiro@hotmail.com

Luciano Silva

Graduado em Tecnologia em Manutenção Industrial

FATEC Osasco

luciano.silva7245@gmail.com

\section{Reginaldo Machado}

Graduado em Tecnologia em Manutenção Industrial

FATEC - Osasco

regis2870@gmail.com

\section{Willian Aurelio Nogueira}

Doutor em Engenharia Elétrica pela Escola Politécnica da Universidade de São Paulo

Professor da FATEC - Osasco

willian.nogueira@fatec.sp.gov.br

\section{Antonio Carlos Santos de Arruda}

Mestre em Engenharia Elétrica pela Escola Politécnica da Universidade de São Paulo Professor da FATEC - Osasco antonio.arruda@fatec.sp.gov.br

1 Os autores deste projeto agradecem às seguintes pessoas que contribuíram com a realização deste projeto: Professor Dr. Alexandre Ichiro Hashimoto; Professor Especialista Carlos Alberto de Freitas; Professor Especialista Fábio Noguti;Técnico de Laboratório Paulo Ferreira Rosa; Professor Dr. Ronaldo Willian Reis; Sr. Ariovaldo, da empresa RN Usinagens, pela doação de matéria prima e máquina para usinagem; Sr. Edilson, da empresa Global Moldes, pela doação de matéria prima.

\footnotetext{
${ }^{2}$ Autor para correspondência: Faculdade de Tecnologia do Estado de São Paulo, Rua Pedro Rissato, 30, Vila dos Remédios, Osasco - SP, Brasil - CEP 06296-220.
}

REMIPE- Revista de Micro e Pequenas Empresas e Empreendedorismo da Fatec Osasco V. 4 No2, jul.-dez. 2018. 


\section{Raphael Garcia Moreira}

Doutor em Engenharia Elétrica pela Escola Politécnica da Universidade de São Paulo

Professor da FATEC - Osasco

raphaelgarciamoreira@gmail.com

RESUMO: Existe um mercado promissor de deposição de filmes finos metálicos para aplicações de alta tecnologia no Brasil. Esse mercado não tem sido explorado pelos microempreendedores por falta de um estudo de viabilidade básico da construção de equipamentos que possam evaporar metais com qualidade e controle. Neste trabalho, foi feito um estudo de viabilidade da construção de uma evaporadora de metais que foi construída para uma primeira avaliação prática. Os resultados sugerem que com investimentos da ordem de $\mathrm{R} \$ 4.000,00$ a $\mathrm{R} \$ 15.000,00$, é possível fabricar evaporadoras de filmes finos com qualidade industrial. Uma atenção especial deve ser dada ao circuito de vácuo para controle da qualidade do filme depositado. $\mathrm{O}$ mercado pode ser facilmente explorado no desenvolvimento e fabricação de placas de energia solar, deposição de camadas metálicas em vidros instalados em automóveis, antenas de satélites e até na fabricação de joias e bijuterias.

Palavras-chave: evaporadora de metais; evaporação; filmes finos; metalurgia; microeletrônica.

ABSTRACT: There is a promising market for the deposition of metallic thin films in terms of high technology applications in Brazil. This market has not been explored by microentrepreneurs because there is no a study which shows the basic viability to build a piece of equipment which can evaporate metals with quality and control. In this work, a viability research was carried out on the construction of a metal evaporator and, moreover, it was built for a first practical evaluation. The results suggest that with investments of the order from $R \$ 4,000.00$ to $R \$ 15,000.00$, it is possible that the microentrepreneur may manufacture industrial grade thin film evaporators. Special attention must be given to the vacuum circuit in order to control the quality of the deposited film. The market can be easily explored in terms of the development and manufacturing of solar energy plates, deposition of metal layers in automotive glass, satellite antennas and even in the manufacturing of jewelry and costume jewelry.

Keywords: evaporator of metals; evaporation; thin films; metallurgy; microelectronic.

\section{INTRODUÇÃO}

Há abundância de oportunidades de aplicações comerciais de técnicas de deposição de filmes finos, tais como: com evaporação térmica, sputtering, moagem mecânica, precipitação química, síntese de plasma térmico, entre outros (KERMASHA; GOETGHEBEUR; DUMONT, 1995).

Entre as técnicas acima mencionadas, destaca-se a evaporação térmica devido ao grande número de aplicações que atingiu ao longo dos anos, sendo uma das técnicas mais 
antigas de deposição de filmes finos, também, é uma das mais amplamente empregadas (KERN, 2012).

A técnica de deposição de filmes finos possui ampla faixa de aplicação: seja em microeletrônica, isto é, na fabricação de microchips de alta tecnologia, no desenvolvimento e fabricação de placas de energia solar, deposição de camadas metálicas em vidros instalados em automóveis, antenas de satélites e até na fabricação de joias e bijuterias (KERN, 2012; THONGNOPKUN; JAMKRATOKE; EKGASIT, 2012).

\section{FUNDAMENTAÇÃO TEÓRICA}

A evaporação térmica é um processo bem conhecido do estado da arte (HEAVENS, 1952) e consiste de um filamento com ponto de fusão suficientemente maior do que o do material a ser evaporado que é posicionado em contato com o dito filamento. Quando o filamento alcança a temperatura de fusão em alto vácuo, ocorre uma rápida evaporação do material. $\mathrm{O}$ vapor do material evaporado se dispersa pelo vácuo, produzindo uma frente de vapor com formato parabólico que produz um gradiente de espessura ao longo do alvo (HEAVENS, 1952).

Tipicamente, o filamento consiste de tungstênio e, para uma ampla faixa de aplicações, o alumínio é o material a ser evaporado (HEAVENS, 1952; SAYER; SREENIVAS, 1990). 
A Figura 1 mostra um esquema de funcionamento básico da evaporadora térmica:

Figura 1. Esquema de funcionamento básico de uma evaporadora térmica:

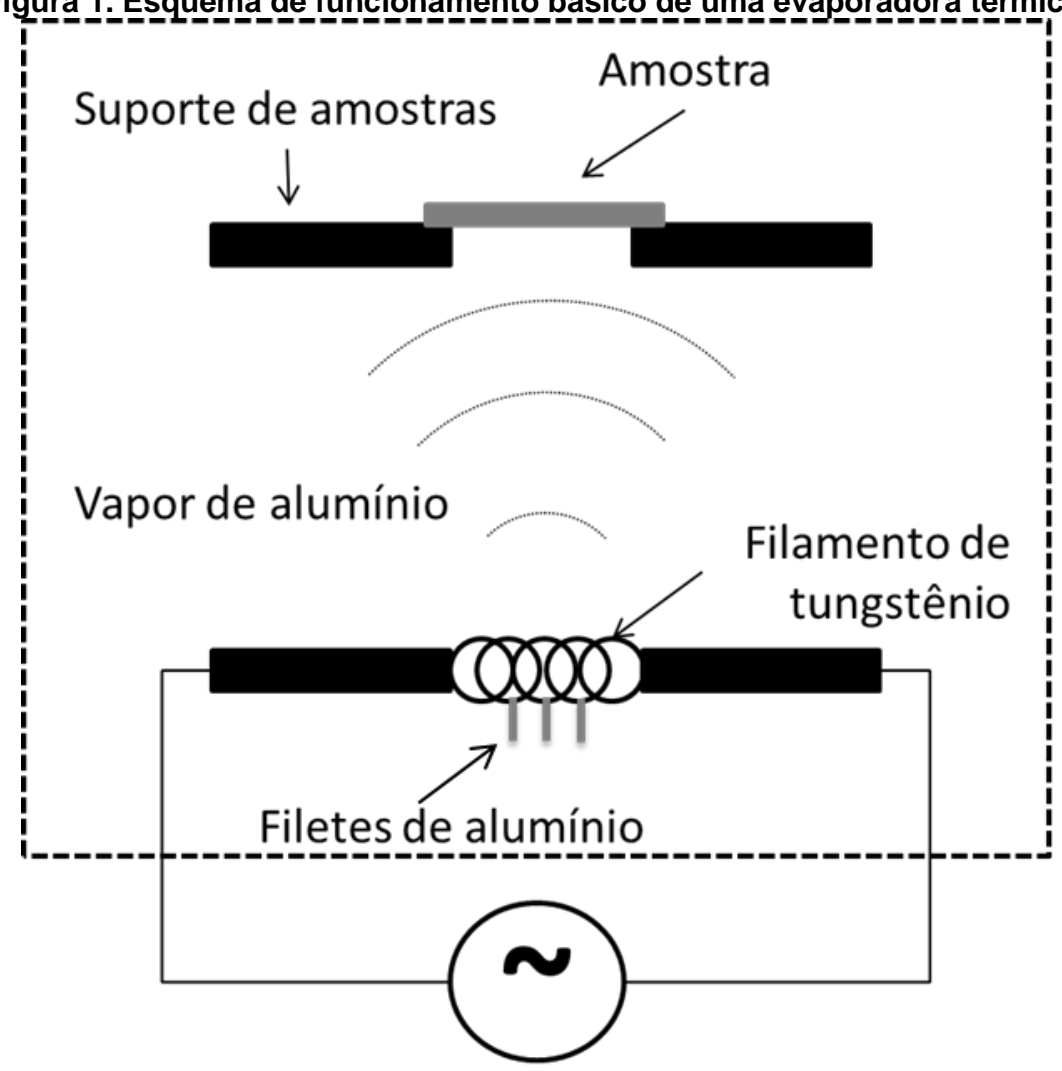

Fonte: Elaborado pelos Autores.

A espessura do filme depositado é inversamente proporcional à distância entre o filamento e a amostra. Por outro lado, quanto mais distante a amostra do filamento, menor será o gradiente de espessura observado na amostra, uma vez que a parábola da frente do vapor de metal tende a ficar plano com a distância (HEAVENS,1952; SAYER; SREENIVAS, 1990).

O metal tende a ser depositado com baixa rugosidade em alto vácuo (da ordem de $1 \times 10^{-10} \mathrm{~m}$ ), ou seja, para pressões da ordem de $1 \times 10^{-6} \mathrm{mmHg}$, já em pressões maiores, a literatura reporta a provável oxidação do vapor e formação de óxidos no processo de deposição (SAYER, M.; SREENIVAS, K., 1990).

\section{JUSTIFICATIVA}

O Brasil apresenta grandes oportunidades para exploração da energia solar (TIMILSINA; KURDGELASHVILI; NARBEL, 2012) na área de joalheria de luxo e bijuterias (GASPERINI; REICHELT, 2010), microeletrônica (AMANN; CANTWELL, 2012), entre outros.

REMIPE- Revista de Micro e Pequenas Empresas e Empreendedorismo da Fatec Osasco V. 4 N², jul.-dez. 2018. 
Deve ser realçada a massa crítica de projetistas de dispositivos microeletrônicos no Brasil, com capacidades para desenvolver microchips ou placas de energia solar que hoje precisam terceirizar parte da fabricação dos protótipos em centros de pesquisa e desenvolvimento europeus como forma de atender a demanda (SWART et al., 2012). Esses projetistas podem ser atendidos por equipamentos nacionais. Isso representa uma oportunidade aos microempreendedores de alta tecnologia.

\section{OBJETIVOS DO PROJETO}

O objetivo geral deste trabalho consiste em verificar a viabilidade de fabricação de uma evaporadora térmica de metais de baixo custo, apropriada para os recursos disponíveis no município de Osasco, no Estado de São Paulo, visando a fabricação em escala por microempreendedores individuais de alta tecnologia. Os objetivos específicos são:

- fabricar uma estrutura móvel para suportar o sistema de evaporação térmica, uma vez que microempreendedores possuem a necessidade de equipamentos fáceis de transportar;

- fabricar a campânula em aço inoxidável, visando limitar a contaminação para o filme a ser depositado;

- fabricar o suporte do filamento para temperaturas de até $2500{ }^{\circ} \mathrm{C}$;

- fabricar o sistema de vácuo e sistema elétrico de controle;

- realizar um levantamento de custos como estimativa da viabilidade de fabricação a partir das condições de um microempreendedor.

\section{MATERIAIS E MÉTODOS}

\subsection{LEVANTAMENTO DOS PRINCIPAIS MATERIAIS PARA FABRICAÇÃO DE UM FORNO E RESPECTIVOS PREÇOS}

Como metodologia de planejamento, foram inicialmente pesquisados fornecedores de materiais da região de Osasco, contudo, alguns materiais foram adquiridos de outras regiões, conforme a 
Tabela 1:

Tabela 1. Lista de materiais e preços para fabricação do forno conforme especificações:

\begin{tabular}{|c|c|c|}
\hline NOME & MODELO & PREÇO \\
\hline Tubo retangular & Aço carbono $(50 \times 30 \mathrm{~mm}) 7$ barras de $6 \mathrm{mts}$ & $\mathrm{R} \$ 385,00$ \\
\hline Chapa galvanizada & Aço carbono $(1500 \times 1000 \mathrm{~mm})$ & $\mathrm{R} \$ 45,00$ \\
\hline Chapa acrílica & $1000 \times 300 \times 4 \mathrm{~mm}$ & $R \$ 35,00$ \\
\hline Câmpanula & Aço inox $(300 \times 500 \mathrm{~mm})$ & $\mathrm{R} \$ 500,00$ \\
\hline Disco de inox & Aço inox (300 mm) & $\mathrm{R} \$ 100,00$ \\
\hline Parafusos & Inox m5x70mm (4 unid) & $\mathrm{R} \$ 10,00$ \\
\hline Manta de silicone & $400 \times 400 \times 3 \mathrm{~mm}$ & $\mathrm{R} \$ 45,00$ \\
\hline Chapa Perfurada & Esp.1.2 Furo 6.35 & $\mathrm{R} \$ 60,00$ \\
\hline Bomba de vácuo & Duplo estágio DVP 3A, 6 CFM 170L /M & $R \$ 500,00$ \\
\hline Mangueira & Flexível 500 x mm x 1/2" & $\mathrm{R} \$ 40,00$ \\
\hline Manômetro & Dupla escala 0-30 inhg & $\mathrm{R} \$ 20,00$ \\
\hline Flange elétrico & Flange com seis pinos para ligação & $\mathrm{R} \$ 860,00$ \\
\hline Transformador & Tensão entrada $220 \mathrm{~V}$, saída $10 \mathrm{~V}$ & $\mathrm{R} \$ 560,00$ \\
\hline Variac & Variador de tensão de (0 á 220V / 50 A) & $\mathrm{R} \$ 400,00$ \\
\hline Componentes elétricos & $\begin{array}{l}\text { Painel,disjuntores,contatores, } \\
\text { fusíveis,cabos, botão etc. }\end{array}$ & $\mathrm{R} \$ 250,00$ \\
\hline Outros & Veniz e tinta & $\mathrm{R} \$ 40,00$ \\
\hline Total & & $\mathrm{R} \$ \mathbf{3 . 8 5 0 , 0 0}$ \\
\hline
\end{tabular}

O projeto partiu de um investimento estimado de $\mathrm{R} \$ 3.850,00$, um valor compatível com a capacidade de investimento de microempreendedores de São Paulo (SOUZA; ROMEIRO, 2017).

\subsection{PROJETO GERAL}

O projeto da evaporadora foi realizado com uma licença acadêmica do SolidWorks. A Figura 2 mostra as principais dimensões, materiais e suas posições no projeto, conforme seguem:

REMIPE- Revista de Micro e Pequenas Empresas e Empreendedorismo da Fatec Osasco V. 4 N², jul.-dez. 2018. 
Figura 2 - Vista do projeto 2D da evaporadora. Medidas em milímetros:
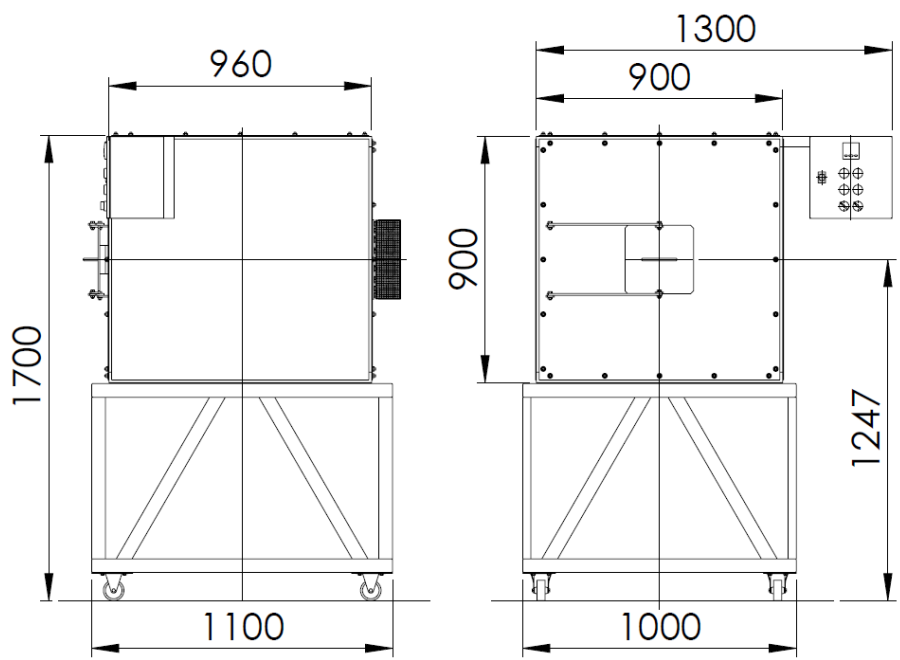

Fonte: Acervo pessoal.

A potência aplicada sobre o filamento foi de aproximadamente $800 \mathrm{~W}$ e confeccionadas em tungstênio. A bomba de vácuo foi conectada à campânula por meio de uma válvula de precisão visando prover controle no momento da equalização da pressão interna com o ambiente. Na Figura 3, é apresentado um esquema geral de montagem e fabricação da evaporadora de metais:

Figura 3. Visão do esquema geral da evaporadora de metais fabricada:

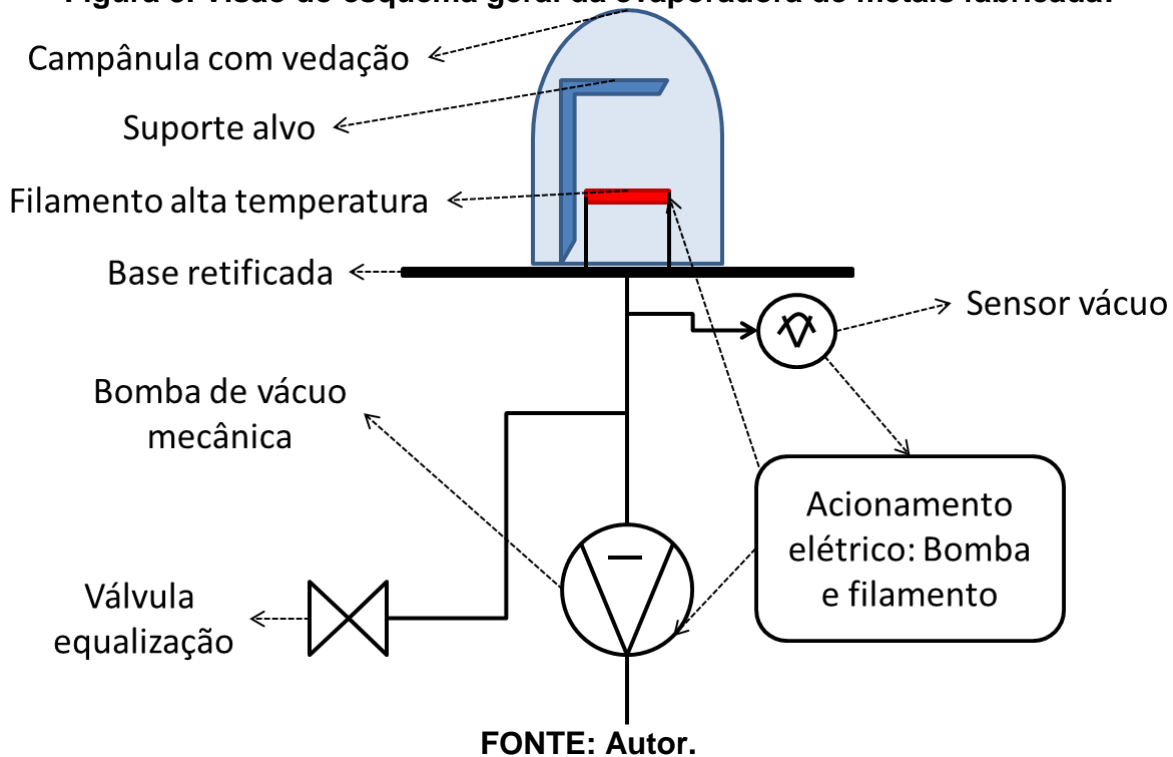

REMIPE- Revista de Micro e Pequenas Empresas e Empreendedorismo da Fatec Osasco V. 4 No2, jul.-dez. 2018. 


\subsection{ETAPAS DE FABRICAÇÃO}

Nas figuras que seguem são mostradas as etapas de fabricação da evaporadora. Deve ser observado que todas as etapas são compatíveis com equipamentos de fácil acesso, podendo ser este projeto realizado por oficinas vinculadas a micro e pequenas empresas. A Figura 4 apresenta o processo de soldagem da estrutura externa:

Figura 4. Soldagem das estruturas externas do forno usando processo MIG/MAG:

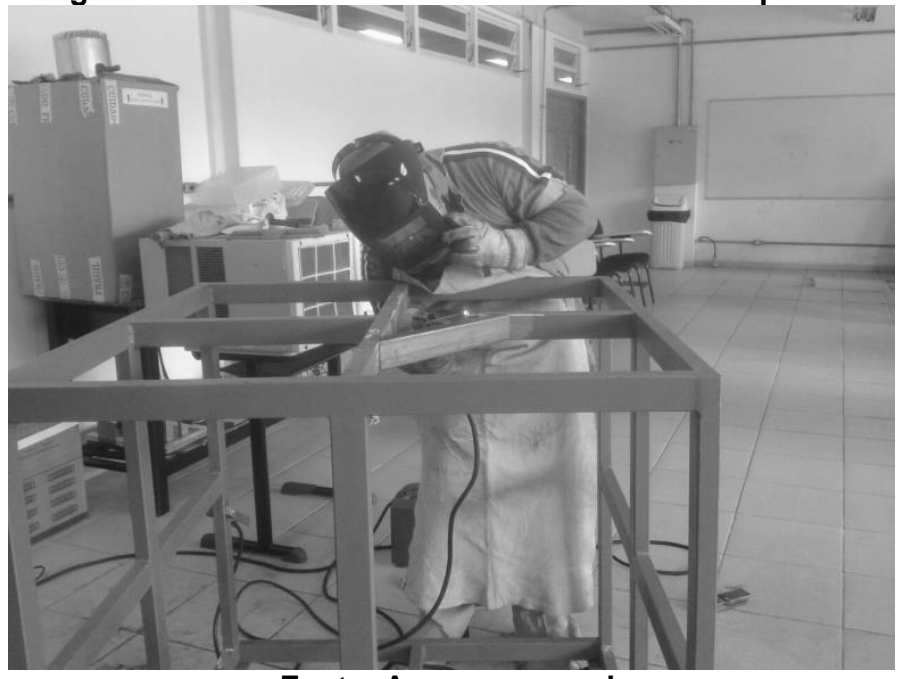

Fonte: Acervo pessoal.

A Figura 5 mostra o delicado processo de ajustes da estrutura para acomodação dos componentes constituintes do sistema (conforme listados na tabela 1)

REMIPE- Revista de Micro e Pequenas Empresas e Empreendedorismo da Fatec Osasco V. 4 No2, jul.-dez. 2018. 
REMIPE

Figura 5. Detalhes dos processos de ajustes estruturais empregando ferramentas acessíveis ao microempreendedor:

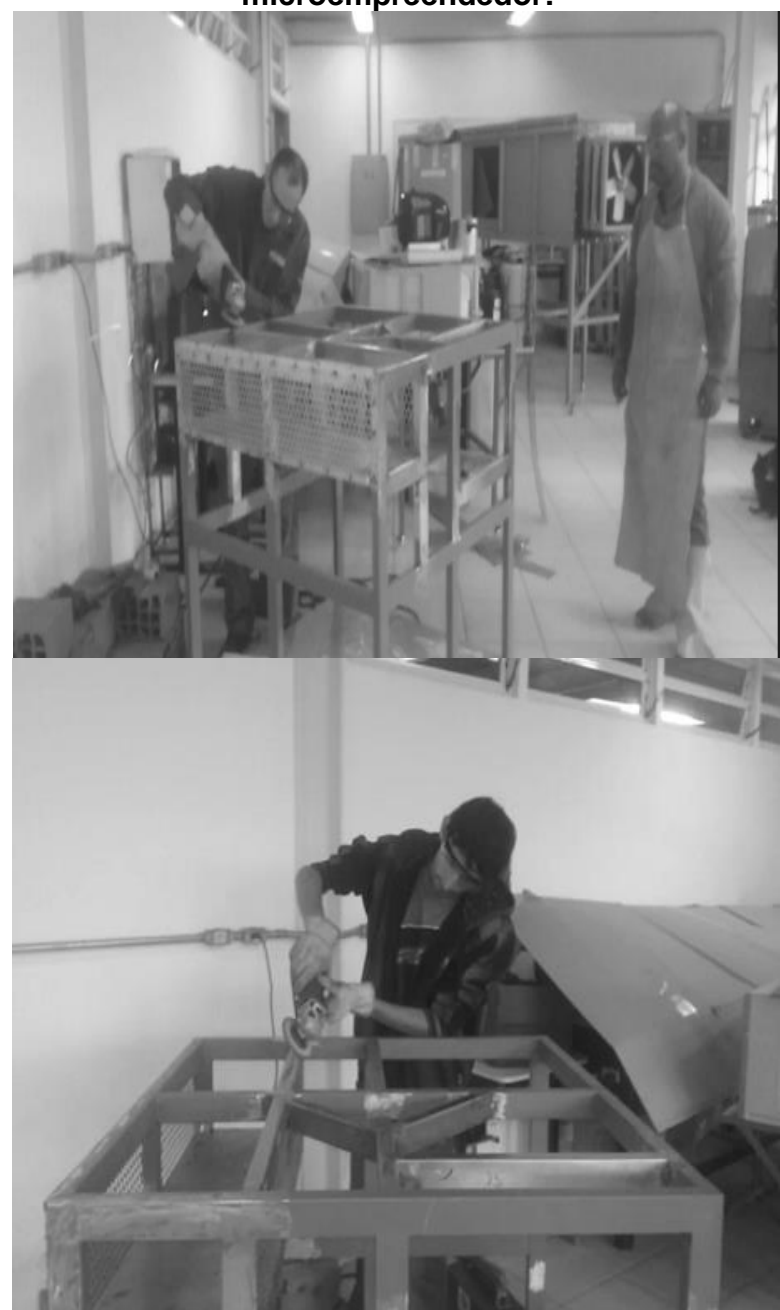

Fonte: Acervo pessoal.

Foi elaborado um controle elétrico apropriado para ligar e desligar o sistema de vácuo e aplicação de potência ao filamento. O ajuste de potência do filamento foi feito por meio de um regulador de tensão tipo VARIAC de 0 a 250 Vac, com corrente máxima de saída de 50 A. Para testes, foi depositado um filme fino sobre uma lâmina de silício proveniente de refugo de processos de microeletrônica conforme Figura 6, a qual mostra uma lâmina que receberá a deposição de filme fino:

REMIPE- Revista de Micro e Pequenas Empresas e Empreendedorismo da Fatec Osasco V. 4 No2, jul.-dez. 2018. 
Figura 6. Lâmina de silício empregada para testes durante os processos de deposição:

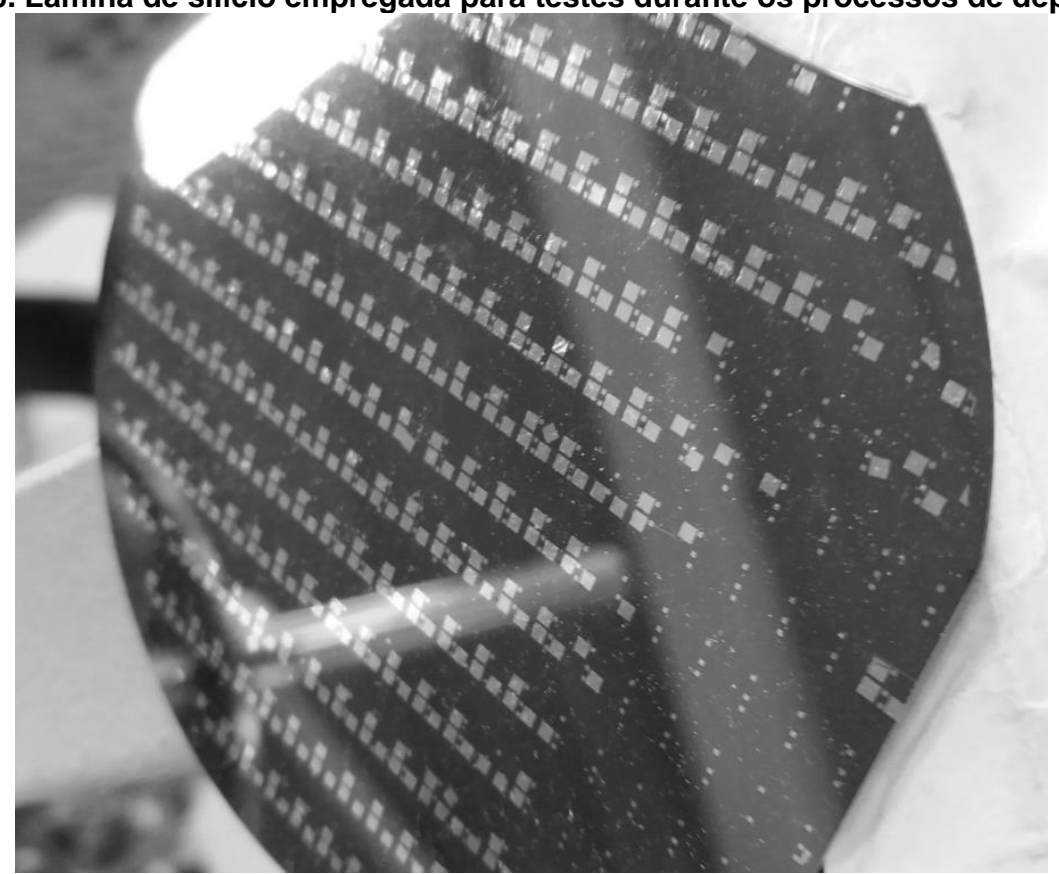

Fonte: Acervo pessoal.

\section{APRESENTAÇÃO E ANÁLISE DOS RESULTADOS}

A fabricação de uma evaporadora de metais visando prestação de serviços de desenvolvimento de novos materiais e processos para a indústria metalúrgica, cerâmica, de polímeros e de eletrônica foi concluída com sucesso conforme Figura 7:

REMIPE- Revista de Micro e Pequenas Empresas e Empreendedorismo da Fatec Osasco V. 4 N², jul.-dez. 2018. 
Figura 7. Vista do forno totalmente concluído e operacional:

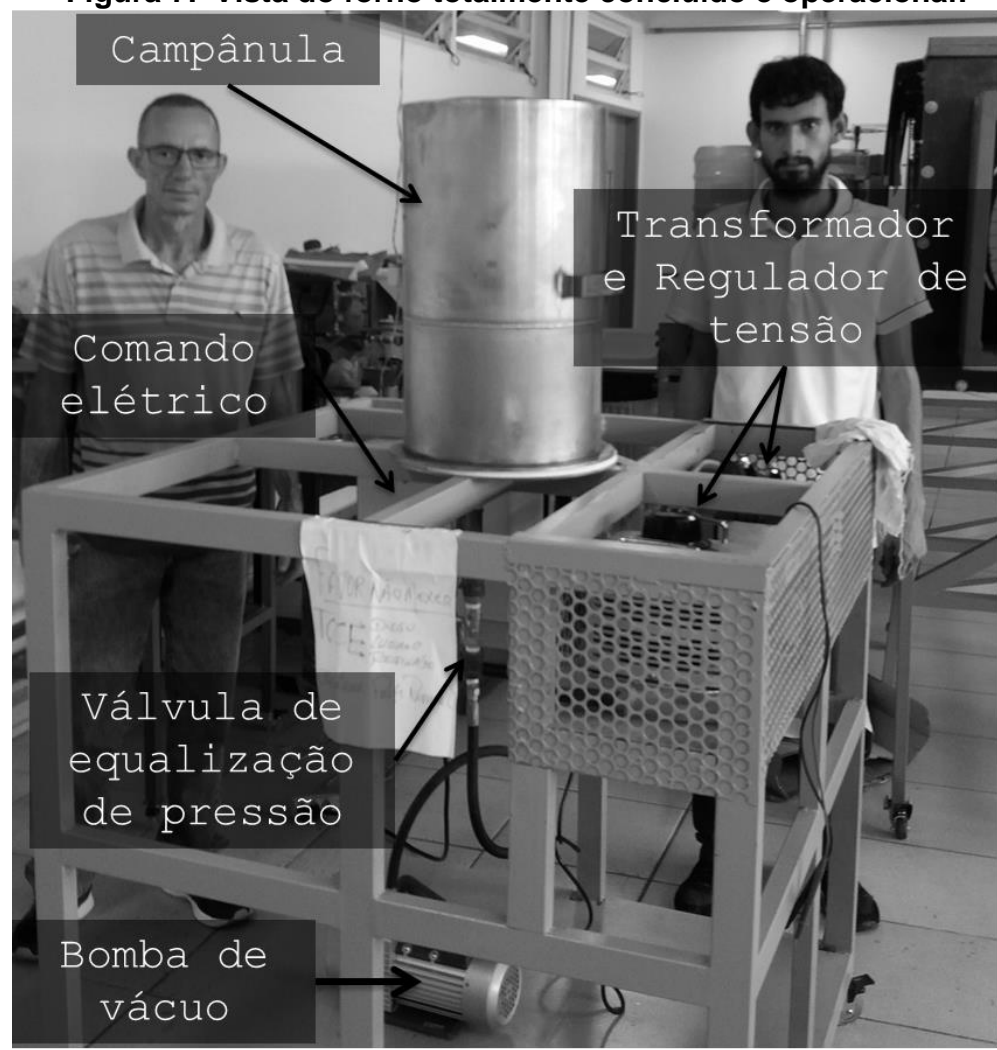

Fonte: Acervo pessoal.

Um primeiro teste foi realizado visando evaporar o alumínio. Esse teste teve a finalidade de caracterizar os principais parâmetros do evaporador de metais, tais como: rampa de aquecimento, resfriamento, características de operacionalidade, eficiência da energética visando segurança dos operadores e demais aspectos técnicos, de acordo com a Figura 8:

REMIPE- Revista de Micro e Pequenas Empresas e Empreendedorismo da Fatec Osasco V. 4 No2, jul.-dez. 2018. 
Figura 8. Disposição do suporte e filamento com massas de alumínio preparadas para evaporação:

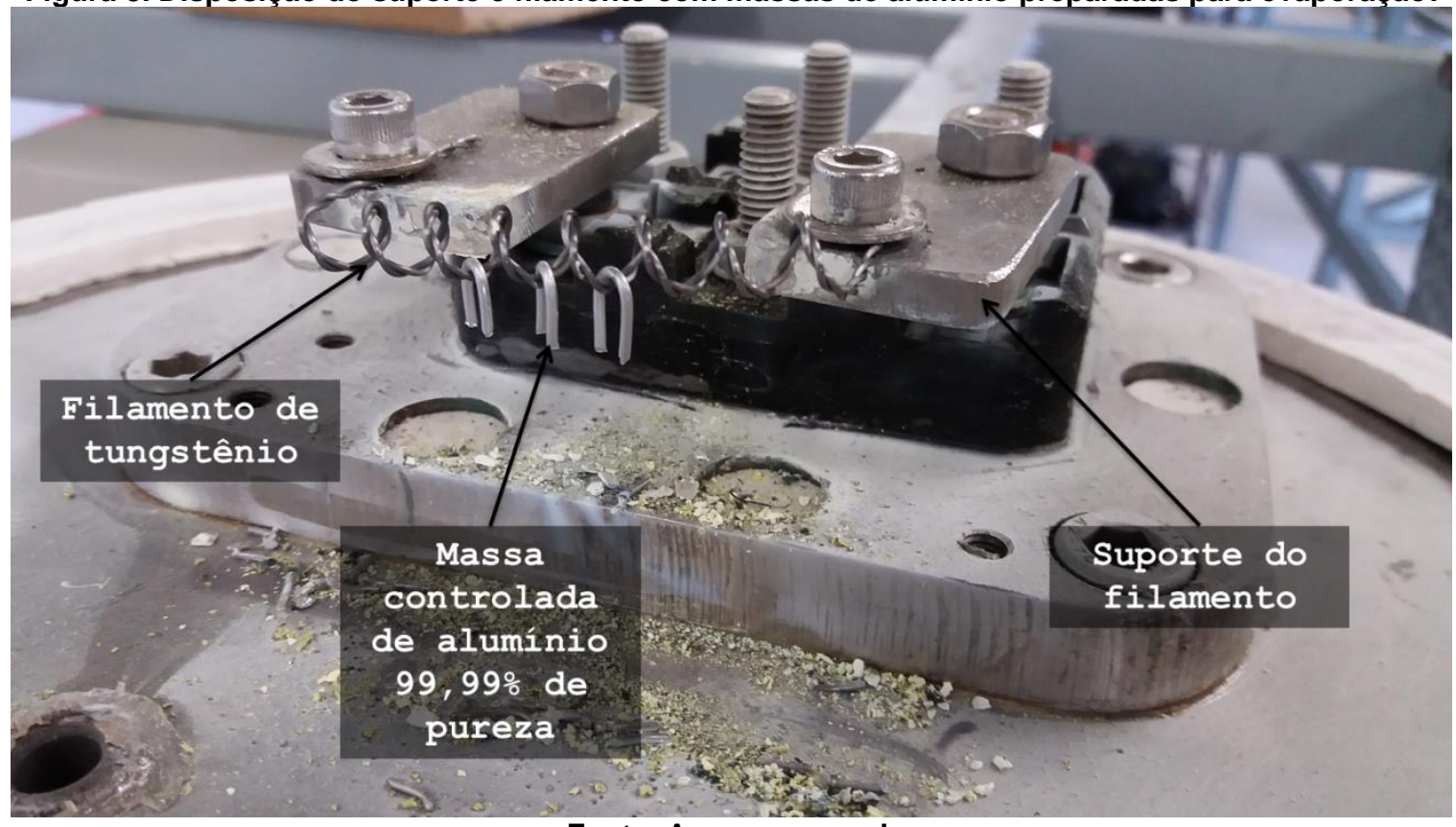

Fonte: Acervo pessoal.

Para caracterizar o processo de aquecimento do filamento, esse recebeu $20 \%$ da potência nominal em pressão atmosférica para verificação e constatação da operacionalidade do sistema, conforme Figura 9:

Figura 9. Indicação visual do aquecimento do filamento de tungstênio:

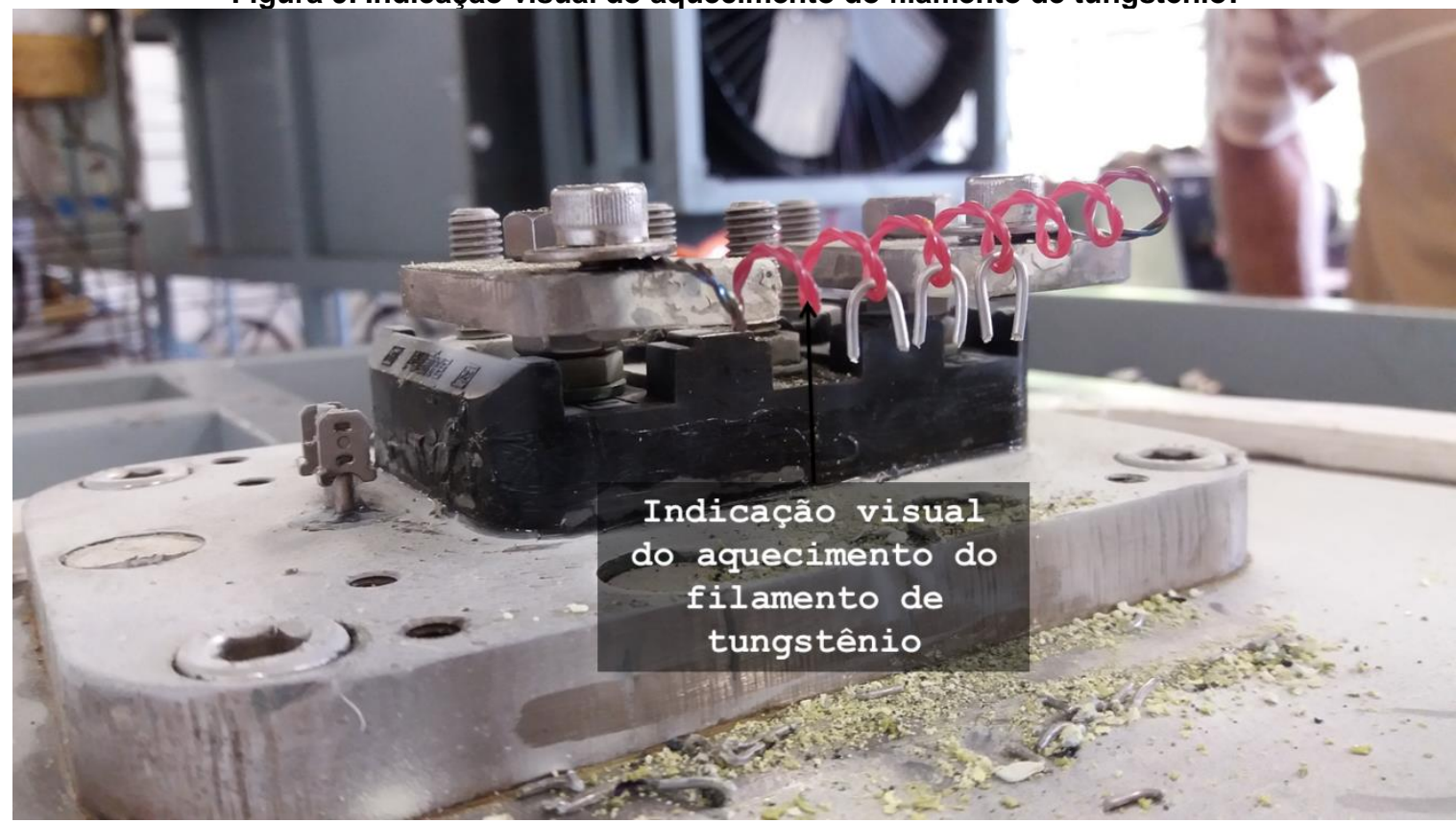

Fonte: Acervo pessoal.

Na Figura 10, são mostrados o regulador de tensão e medidor de corrente elétrica:

REMIPE- Revista de Micro e Pequenas Empresas e Empreendedorismo da Fatec Osasco V. 4 No2, jul.-dez. 2018. 
Figura 10. Controle de tensão e corrente empregado durante as evaporações:

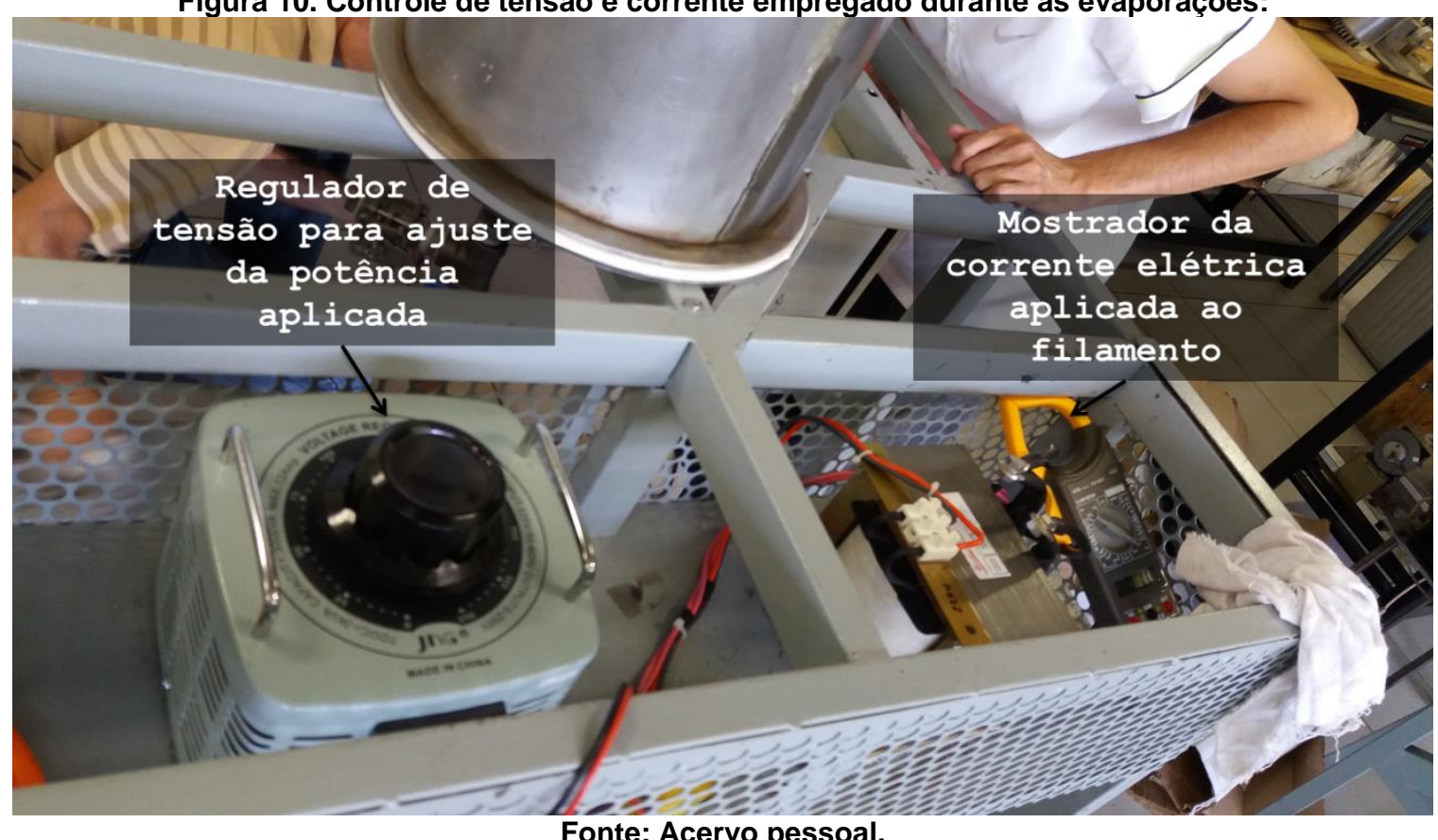

Fonte: Acervo pessoal.

A pressão típica para garantir um vácuo suficiente para deposição de filmes finos de alta qualidade é da ordem $1,0 \times 10^{-6} \mathrm{mmHg}$ (HEAVENS, 1952). Por outro lado, com a bomba de vácuo empregada, especificada para aplicações de manutenção em ar-condicionado, foi possível obter uma pressão da ordem de $50 \mathrm{mmHg}$ (a pressão atmosférica é de $760 \mathrm{mmHg}$ ), conforme Figura 11:

REMIPE- Revista de Micro e Pequenas Empresas e Empreendedorismo da Fatec Osasco V. 4 No2, jul.-dez. 2018. 
Figura 11. Mostrador mecânico de pressão. Indicação de 50 mmHg:

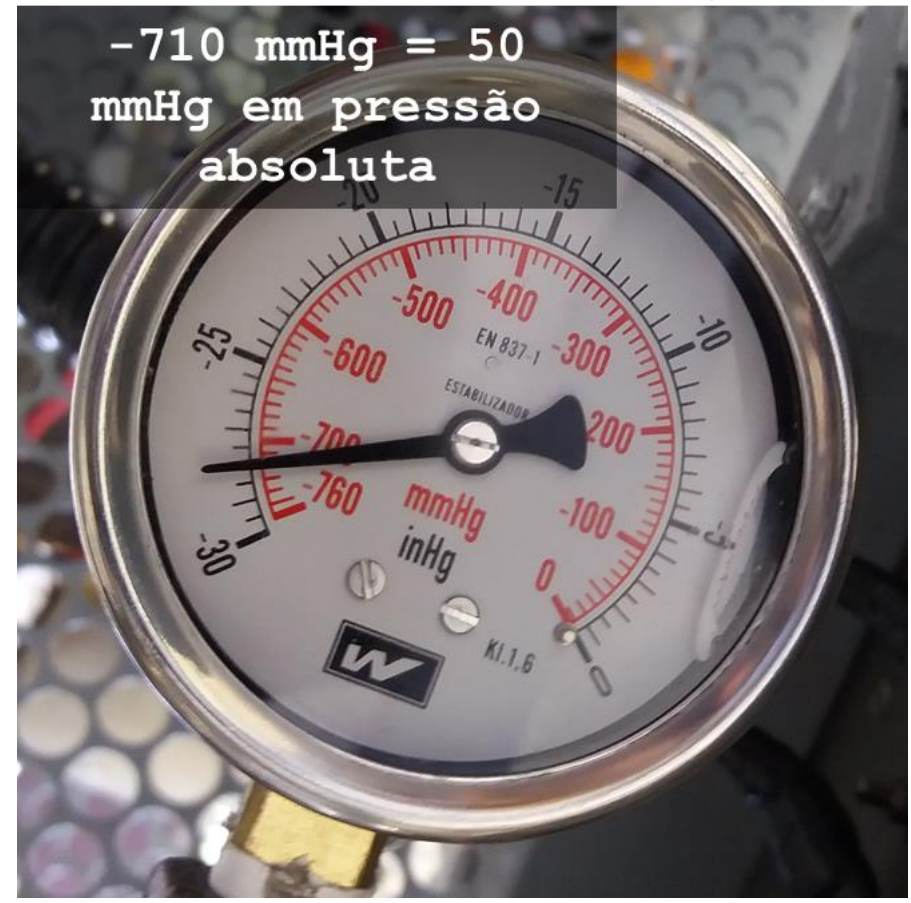

Fonte: Acervo pessoal.

Foi projetado um sistema de suporte para alvos do tipo lâmina de silício e um mecanismo para ajuste da altura entre filamento e alvo, de acordo com o que foi mostrado na Figura 12. Esse ajuste na altura permite o controle da espessura do filme a ser depositado (observar comentários sobre a Figura 1).

Figura 12. Sistema de suporte de lâminas/alvo e ajuste de altura dos alvos em relação ao filamento:

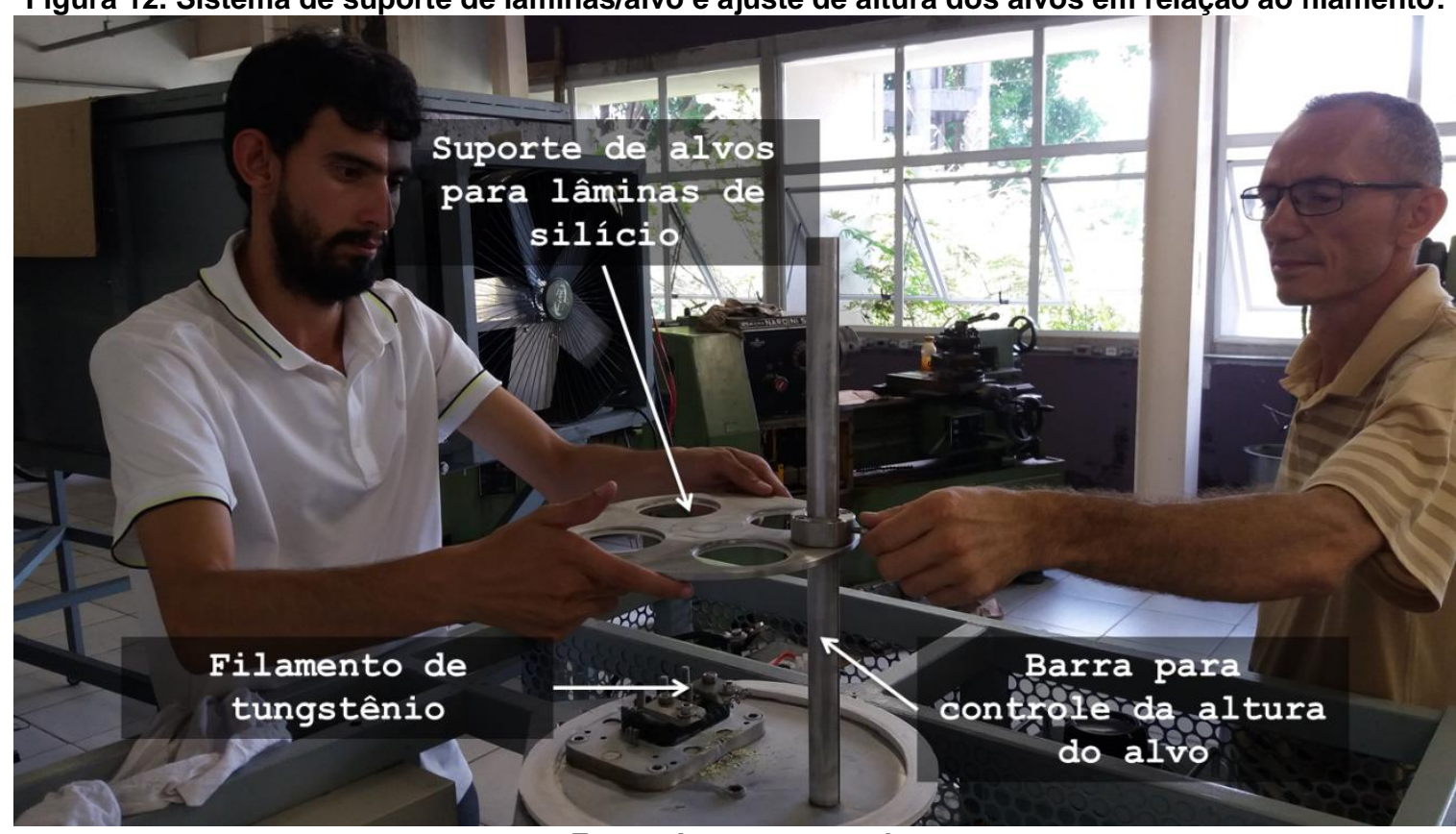

Fonte: Acervo pessoal.

REMIPE- Revista de Micro e Pequenas Empresas e Empreendedorismo da Fatec Osasco V. 4 N², jul.-dez. 2018. 
Como resultado final, após o processo de evaporação foi observada a presença de uma fina camada fosca e de cor branca sobre a lâmina enquanto que o alumínio foi consumido. A literatura reporta que em pressões elevadas, acima de $1 \times 10^{-2} \mathrm{mmHg}$, o alumínio é depositado na forma de $\mathrm{Al}_{2} \mathrm{O}_{3}$ (alumina), ou seja, devido a alta quantidade de oxigênio, o alumínio é oxidado durante a trajetória que percorre entre o filamento e o alvo (SAYER; SREENIVAS, 1990), conforme a

Figura 13:

Figura 13. Depósito de uma fina camada de óxido, devido a pressão elevada de $50 \mathrm{mmHg}$ :

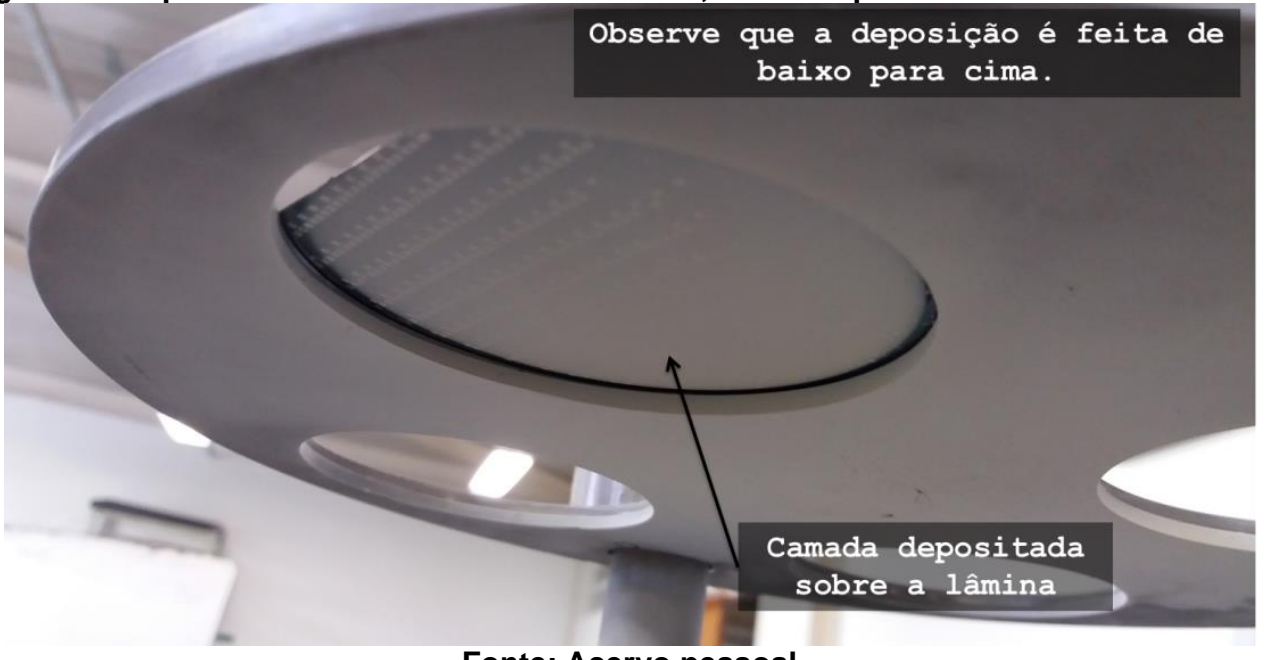

Fonte: Acervo pessoal.

O metal foi evaporado, contudo, melhoras no sistema de vácuo devem ser efetuados para viabilizar completamente o sistema de deposição de metais, visando obter filmes metálicos sobre o alvo.

\section{CONSIDERAÇÕES FINAIS}

Uma evaporadora de metais visando serviços de desenvolvimento de novos materiais e processos para a indústria metalúrgica, cerâmica, de polímeros e de microeletrônica foi concluída e testada. Como teste inicial, o alumínio foi evaporado e depositado na forma de $\mathrm{Al}_{2} \mathrm{O}_{3}$ (alumina).

O projeto se mostrou bastante competitivo e eficiente em termos de custo e operacionalidade. Por outro lado, melhorias no circuito de vácuo devem ser elaboradas, por exemplo, com a instalação de uma bomba de vácuo tipo difusora para obter pressões da ordem de $1 \times 10^{-2} \mathrm{mmHg}$ ou menor.

O mercado relacionado ao desenvolvimento de materiais e processos tecnológicos das áreas de metalurgia, cerâmica, de polímeros e microeletrônica pode ser fortemente 
impulsionado no Brasil se esse tipo de serviço atingir uma massa crítica mínima, isto é, um número mínimo de empresas que possam oferecê-lo a um preço de mercado acessível a todos os interessados.

Como perspectivas futuras são sugeridas para o presente trabalho as seguintes atividades:

- instalação de uma bomba difusora no circuito de vácuo, permitindo obter vácuo da ordem de $1 \times 10^{-2} \mathrm{mmHg}$ ou menor;

- teste com outros tipos de metais, além do alumínio;

- instalar visor na campânula;

- caracterizar e desenvolver uma equação que relacione altura entre filamento e alvo como forma de previsão da espessura do filme fino depositado;

- caracterização dos filmes finos depositados;

\section{REFERÊNCIAS}

AMANN, Edmund; CANTWELL, John (Ed.). Innovative firms in emerging market countries. Oxford University Press, 2012.

GASPERINI, Chaline; REICHELT, Valesca Persch. Mercado de luxo: estratégias para internacionalização de empresas joalheiras do Brasil. Internext, v. 4, n. 2, p. 83-100, 2010.

HEAVENS, O. S. The Contamination in Evaporated Films by the Material of the Source. Proceedings of the Physical Society. Section B, v. 65, n. 10, p. 788, 1952.

KERMASHA, S.; GOETGHEBEUR, M.; DUMONT, J. Determination of phenolic compound profiles in maple products by high-performance liquid chromatography. Journal of Agricultural and Food Chemistry, v. 43, n. 3, p. 708-716, 1995.

SAYER, M.; SREENIVAS, K. Ceramic thin films: fabrication and applications. Science, v. 247, n. 4946, p. 1056-1060, 1990.

SOUZA, Paulo Augusto Ramalho de; ROMEIRO, Maria do Carmo. As instituições de microcrédito no Brasil: uma perspectiva sobre o fluxo de fundos no setor. Revista Contemporânea de Contabilidade, v. 14, n. 33, p. 88-100, 2017.

KERN, Werner. Thin film processes II. Academic press, 2012.

SWART, Jacobus W. et al. Education and jobs on ic design through the ic-brazil initiative. In: European Workshop on Microelectronics Education. 2012. p. 81-84.

THONGNOPKUN, Pimthong; JAMKRATOKE, Matinee; EKGASIT, Sanong. Thermal behavior of nano-silver clay in the application of handmade jewelry. Materials Science and Engineering: A, v. 556, p. 849-854, 2012.

REMIPE- Revista de Micro e Pequenas Empresas e Empreendedorismo da Fatec Osasco V. 4 No2, jul.-dez. 2018. 
TIMILSINA, Govinda R.; KURDGELASHVILI, Lado; NARBEL, Patrick A. Solar energy: Markets, economics and policies. Renewable and sustainable energy reviews, v. 16, n. 1, p. 449-465, 2012.

REMIPE- Revista de Micro e Pequenas Empresas e Empreendedorismo da Fatec Osasco V. 4 No2, jul.-dez. 2018. 